\title{
Light influences feeding and growth of echinoplutei
}

\author{
L. Milonas ${ }^{1}$, B. Pernet ${ }^{2}$, B. L. Bingham ${ }^{1, *}$ \\ ${ }^{1}$ Department of Environmental Sciences, Western Washington University, Bellingham, Washington 98225, USA \\ ${ }^{2}$ Department of Biological Sciences, California State University, Long Beach, Long Beach, California 90840, USA
}

\begin{abstract}
Because planktonic invertebrate larvae may be food-limited, anything that increases feeding and digestive efficiency should increase the chances of larval survival to metamorphosis. As light directly enhances both feeding and digestion in some planktonic heterotrophic protists, we hypothesize that similar processes might occur in the larvae of marine invertebrates. We studied the direct effects of light on feeding and development in sea urchin larvae (Strongylocentrotus droebachiensis, S. franciscanus and sand dollar Dendraster excentricus). Larvae were placed in 12:12 h light:dark cycles or in complete darkness and ingestion rates were measured. We monitored larval morphology during the first 2 to $3 \mathrm{wk}$ of development and tested for light-related differences. Shortterm changes in light regime had no effect on feeding rates. However, larvae of all 3 species showed longer-term diel feeding patterns with ingestion rates generally higher during daylight hours. These patterns persisted in $S$. franciscanus larvae even when larvae were held in complete darkness for $3 \mathrm{~d}$. Larvae of $D$. excentricus exposed to natural light cycles developed longer arms usually associated with food limitation; those held in darkness had significantly shorter arms. The developing juvenile structures (i.e., rudiments) of $S$. droebachiensis larvae exposed to light were significantly smaller than those of larvae held in continuous darkness, suggesting that light may have negative effects on larval growth and development. Measuring the effects of light on feeding and growth may clarify the behaviors of invertebrate larvae during their critically important planktonic period.
\end{abstract}

KEY WORDS: Light effects · Larval feeding $\cdot$ Larval growth $\cdot$ Larval morphology

Resale or republication not permitted without written consent of the publisher

\section{INTRODUCTION}

Many marine invertebrates produce planktothrophic larvae that must feed to fuel growth and tissue differentiation during their planktonic periods. Such larvae undergo considerable mortality while in the plankton (Thorson 1950, Young \& Chia 1987, Rumrill 1990, Morgan 1995). Field sampling and laboratory experiments suggest that low natural food levels may limit growth and development of planktotrophic larvae (Paulay et al. 1985, Olson \& Olson 1989, Fenaux et al. 1994, Sulkin et al. 1998, Hansen 1999, Fotel et al. 1999), potentially increasing the length of the larval planktonic period. Because increased time in the plankton increases the risk of being killed by predators, selection for rapid development should optimize the feeding and digestive efficiency of the dispersing larvae.

Light enhances feeding rate and digestion in some planktonic heterotrophic protists. Strom (2001) found that exposure to light caused (1) a 2- to 7-fold enhancement of ingestion rate in the ciliates Coxliella sp. and Strombidinopsis acuminatum, (2) a 40-fold increase in food vacuole loss rate (a measure of digestion) in the heterotrophic dinoflagellate Noctiluca scintillans, and (3) a 20-fold increase in overall population growth rate of Coxliella sp. Strom (2001) hypothesized that light causes chlorophyll photosensitization in the ingested algal cells, producing reactive oxygen species in the protist food vacuole. The reactive oxygen species presumably break down organic matter in the algal cells, attacking lipids, proteins and nucleic acids. As a result, the heterotrophic protists in the light get a digestive boost as oxidative reactions break organic matter down into smaller compounds that are easier to assimilate. Therefore, light increased digestive throughput of algal prey, decreasing vacuole passage time and enabling the protists to ingest and process more algal cells per unit time. This is consistent with the observation of 
Verity (1991) that, at high food concentrations, ciliates can increase their ingestion rate by enlarging vacuole volume or reducing vacuole passage time.

The planktotrophic larvae of marine invertebrates might also respond physiologically or behaviorally to light, benefiting from higher feeding rates or increased digestive efficiency, either of which might lead to more rapid development. The purpose of our study was to test whether light affects feeding and growth in larvae of 3 sea urchin species. We chose these larvae for our experiments because an extensive literature on development and functional morphology of echinoid larvae provides a good basis for interpreting feeding and growth patterns. In addition, several lines of evidence (Fenaux et al. 1994) suggest that echinoid larvae are food-limited in natural waters. We tested the hypothesis that light influences feeding by determining whether (1) larvae have inherent diel feeding patterns (related to light exposure), (2) feeding behavior can be changed by modifying the light regime, (3) growth rate and larval morphology (an index of food availability in larval echinoids) differ when larvae are held in different light conditions.

\section{MATERIALS AND METHODS}

Larval cultures. Sea urchins Strongylocentrotus droebachiensis and $S$. franciscanus were collected from a shallow subtidal population in Burrows Bay, and sand dollars Dendraster excentricus from an intertidal sand flat near East Sound, Orcas Island, Washington, USA. Collections were done in spring of 2002 during months of peak spawning activity: March for S. droebachiensis, April for D. excentricus and May for S. franciscanus.

Sea urchins were induced to spawn in the laboratory by injection of $0.55 \mathrm{M} \mathrm{KCL}$. Eggs from 2 to 3 females were mixed and fertilized with sperm from a single male. Only cultures with $>90 \%$ fertilization were used for experiments. Developing embryos were held at $12^{\circ} \mathrm{C}$ on a $12: 12 \mathrm{~h}$ light:dark cycle (lights on at $06: 00 \mathrm{~h}$, off at 18:00 h) with daily water changes. Once larvae had reached the feeding pluteus stage $(3 \mathrm{~d}$ after fertilization), we maintained them on a mixed diet of the algae Dunaliella tertiolecta $\left(350\right.$ cells $\left.\mathrm{ml}^{-1}\right)$ and Rhodomonas sp. (4000 cells ml ${ }^{-1}$ ), changing the water daily by filtering through a $63 \mu \mathrm{m}$ Nitex filter.

Effect of time-of-day on larval feeding. To test the influence of the light cycle on larval feeding and digestion, we designed an experiment to determine whether there are inherent daily rhythms in larval feeding.

Six to $8 \mathrm{~d}$ after fertilization (depending on the species), we stopped feeding the plutei for $24 \mathrm{~h}$ to clear their guts. We prepared $20 \mathrm{ml}$ glass scintillation vials with 1000 cells ml ${ }^{-1}$ of Rhodomonas sp. and 4000 polystyrene beads $\mathrm{ml}^{-1}$ (10 $\mu \mathrm{m}$ diameter; Polysciences). The beads, which had been soaked in $2.5 \%$ bovine serum albumin for $24 \mathrm{~h}$ to increase their palatability, were readily ingested by larvae; this provided a much clearer measure of ingestion than did algae, which, due to digestion, quickly became uncountable in the stomach. Ten vials were covered with black tape and 10 were left uncovered. Five covered and 5 uncovered vials were prepared for the Dendraster excentricus and Strongylocentrotus franciscanus experiments. Four of each were used to test $S$. droebachiensis.

To start the experiment, we added 15 larvae to each vial, then placed the vials on a plankton roller that turned at ca. $6 \mathrm{rpm}$. Each vial had a small air space to facilitate mixing. The roller was housed in a $12^{\circ} \mathrm{C}$ incubator equipped with wide-spectrum fluorescent bulbs (Sylvania F40/GRO/AQ/WS). Light intensity was ca. $50 \mu \mathrm{mol}$ photons $\mathrm{m}^{-2} \mathrm{~s}^{-1}$ at the level of the vials. We allowed feeding to occur for $15 \mathrm{~min}$, then preserved the larvae by adding buffered formalin (final concentration $10 \%$ ). The feeding trials were kept to $15 \mathrm{~min}$ to ensure that individual beads could still be distinguished in the stomachs.

The experiment was repeated at 07:00, 13:00, 19:00 and 01:00 $\mathrm{h}$ for a total of 40 vials (containing a total of 600 larvae per species) for Dendraster excentricus and Strongylocentrotus franciscanus, and 32 vials (containing a total of 480 larvae) for $S$. droebachiensis. New larvae were used for each trial. Because all larvae were from the same cultures and exposed to the same conditions, any differences in feeding rate over time should have been caused by natural daily patterns of ingestion.

Ingestion rates were measured by counting the beads in the stomachs of 10 to 12 larvae from each vial. Larvae were mounted on microscope slides and flattened with a coverslip, allowing us to accurately count all beads. Data were analyzed as a nested ANOVA with light treatment and time of day as the main factors, vial nested in both light and time and larvae nested in everything. Light and time-of-day were fixed factors while vial and larvae were random. We further analyzed significant time-of-day effects with Tukey's honestly significant difference (HSD) pairwise comparisons. Prior to analysis, we verified that the data met assumptions of normality and homogeneous variance.

Effect of light exposure on larval feeding. To explore whether possible feeding rhythms can be disrupted by changing light conditions, we did an additional test with $22 \mathrm{~d}$ old larvae of Strongylocentrotus franciscanus from the same batch culture described above. In this experiment, half of the larvae were placed in complete darkness for 3 days while the remaining larvae were held in their normal 12:12 h light:dark cycle. 
During their exposure to modified light conditions, it was important that all larvae fed from a common algal pool and were not affected by light-induced differences in food quality. To accomplish this, we constructed a 50 1, rectangular Plexiglas tank that held the algal food supply. A black Plexiglas plate was placed in the top of the tank, resting on 4 wheels that allowed the plate to move back and forth over the surface of the algal pool (Fig. 1). Translucent Tripour beakers (250 $\mathrm{ml}$ ) were hung from circular holes in the plate; the lips of the beakers held them suspended in the algal mixture but off the bottom of the tank. To keep the algal suspension mixed homogeneously throughout the tank and in the test beakers, the Plexiglas plate holding the beakers was attached to a stir motor and the whole plate (with its suspended beakers) acted as a paddle. To permit flow into the beakers, their bottoms were replaced with $80 \mu \mathrm{m}$ Nitex mesh. This held the larvae within the individual beakers while allowing water and food particles to exchange across the Nitex. To enhance flushing across the Nitex, we attached wedges to each corner of the Plexiglas plate. As the stir motor moved the plate back and forth across the tank, the wedges lifted and lowered it, and the beakers it held, pushing water and algae across the Nitex screens.

To control light, we placed the entire tank in a $12^{\circ} \mathrm{C}$ incubator equipped with wide-spectrum fluorescent bulbs on a 12:12 h light:dark cycle. We created light and dark treatments in the tank by wrapping half of the beakers with black plastic and capping them with black Plexiglas discs. The light treatment beakers were capped with clear Plexiglas discs.
For the first $2 \mathrm{~d}$ of the ingestion experiment, the Strongylocentrotus franciscanus larvae were held in the light or dark beakers suspended in the common algal pool of the tank. The algae had been centrifuged to remove the F/2 culturing medium and resuspended in filtered seawater (8000 cells ml $\mathrm{m}^{-1}$ of Rhodomonas sp. and 3000 cells ml $\mathrm{m}^{-1}$ of Dunaliella tertiolecta). The tank was continuously stirred to ensure that all larvae received the same food regardless of their light treatment. One day before measuring ingestion, we moved the larvae to static beakers with no food (still under the same experimental light conditions). After $24 \mathrm{~h}$, the larvae were placed in scintillation vials and tested as described above with light and dark treatments and 4 replicate vials per treatment. Two trials were done, one at 07:00 h, the other at 13:00 h (one of the 13:00 h dark vials was lost due to a handling error). We predicted that the longer treatment exposure would disrupt any inherent feeding behavior, emphasizing the effects of light on ingestion. We counted the number of beads in the stomachs of 12 larvae from each vial and analyzed the data as described above.

To ensure beakers throughout the experimental tank received equal food and suffered no food availability bias, we ran a simple test with no larvae. We filled the tank with $40 \mathrm{l}$ of seawater and added Rhodomonas sp. that had been centrifuged and resuspended in filtered seawater (10000 cells ml $\mathrm{m}^{-1}$ final concentration). We then put 40 , Nitex-bottom beakers in place; 36 were filled with the algal solution while 4 beakers ( 1 in each quadrant of the tank) held only filtered seawater. The tank was allowed to mix for $30 \mathrm{~min}$ with $5 \mathrm{ml}$ samples drawn from the 4 beakers every 1 to $3 \mathrm{~min}$. After

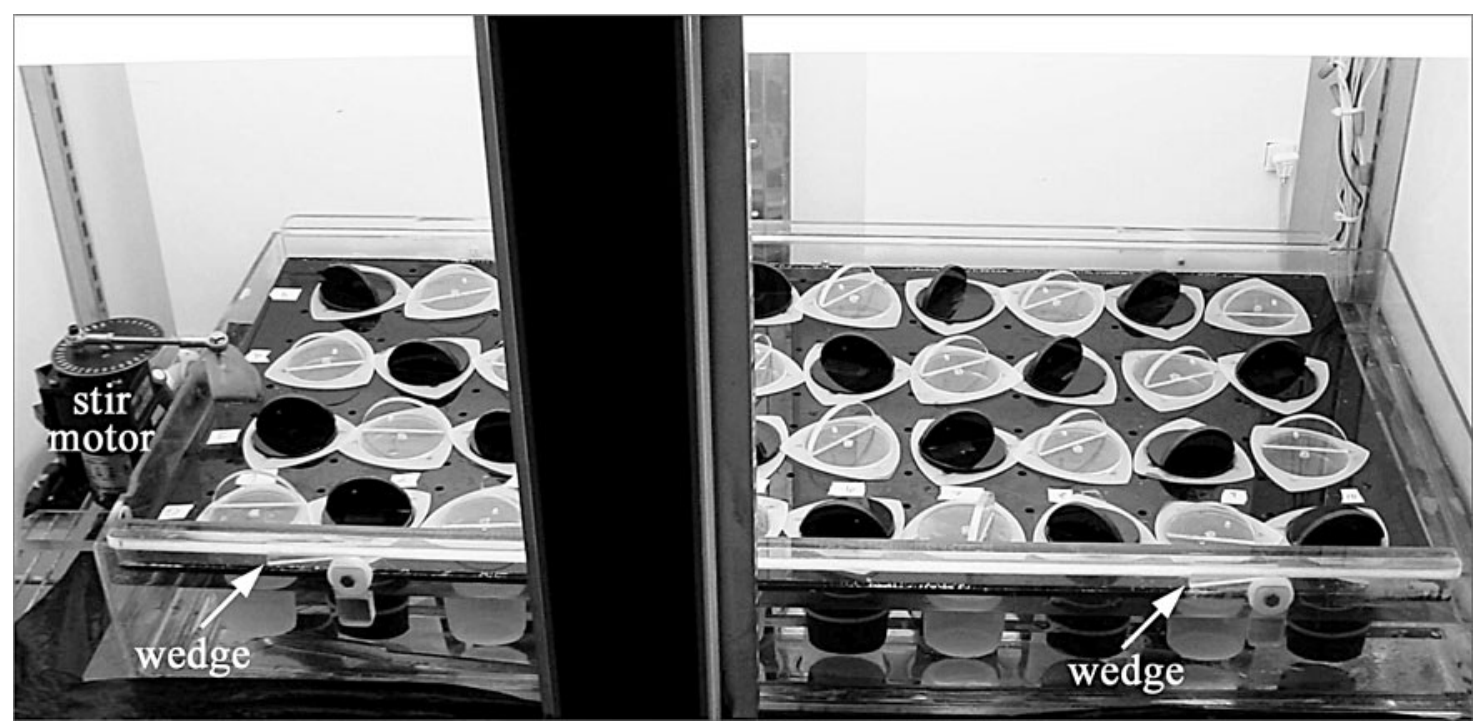

Fig. 1. Experimental tank used to maintain larvae in a homogeneous food suspension despite differences in light/dark conditions. The rollers and wedges moved the plate up and down as the stir motor moved it back and forth across the tank. This ensured mixing and exchange across the Nitex bottoms of the beakers 
30 min, all beakers were removed, the tank contents were thoroughly mixed and 4 additional samples were drawn from the 4 quadrants of the tank as an index of algal abundance in the general algal pool. We used a fluorometer to measure the absorbance of all samples at $663 \mathrm{~nm}$ (to calculate chlorophyll $a$ [chl a] concentration). To ensure no longer-term, treatment-related differences in food availability, we repeated this testing, but with the tank running continuously as it would in an experimental trial (though no larvae were added). After $24 \mathrm{~h}$, we collected a $5 \mathrm{ml}$ sample from the center of all 40 beakers, measured chl a concentration and compared the light and dark treatments with a 1-way ANOVA.

We also documented light levels throughout the tank by systematically alternating 20 light and 20 dark beakers throughout the tank and measuring the light level in the center of each with a Biospherical Instruments QSL $1004 \pi$ PAR sensor. Treatments were compared with a 1-way ANOVA.

Effect of light on growth and larval morphology. To measure effects of light on growth, larvae were fed under light or dark conditions and their development was monitored. Because light could indirectly affect growth by altering food quality, we again used the tank described above. Having determined that food was well mixed in the tank, we prepared our growthrate experiment by centrifuging and resuspending the algal cultures and then adding them to the experimental tank (8000 cells ml ${ }^{-1}$ of Rhodomonas sp. and 3000 cells ml ${ }^{-1}$ of Dunaliella tertiolecta). Final volume in the tank was 401 .

Experiments began when pluteus larvae of the test species (Dendraster excentricus, Strongylocentrotus droebachiensis or S. franciscanus) were added to 20 light and 20 dark beakers suspended in the tank (5 to 8 larvae $\mathrm{ml}^{-1}$ ). Larvae were added to the beakers when they had reached an early pluteus stage $(3 \mathrm{~d}$ after fertilization for $D$. excentricus and $S$. franciscanus, $7 \mathrm{~d}$ for S. droebachiensis). At subsequent 2 to $5 \mathrm{~d}$ intervals, 5 to 8 larvae were collected from each beaker. The sampling was continued until Day 21 for $D$. excentricus, Day 22 for $S$. droebachiensis and Day 14 for S. franciscanus. At 5 dintervals, at least $75 \%$ of the water in the tank was changed and fresh algal food was added.

Sampled larvae were preserved in $10 \%$ buffered formalin and subsequently measured using Bioscan Optimas image analysis software. Because we did not know which larval feature might respond to the light treatments, we measured multiple variables, adding new measurements as new arms appeared on the developing larvae. Measurements included dorsal body length, ventral body length, preoral, anterolateral, postoral, and posterodorsal arm length, body width and rudiment size (Fig. 2). If pairs of arms were unequal in length, only the longer arm was measured as in Strathmann et al. (1992). We measured arms from tip to base on their medial sides because (1) it was easier to determine where arms end on their medial sides, and (2) medial measures give a more accurate indication of length of the cilated band used for larval feeding (McEdward 1984). Body width was measured at the widest point of the body proper just posterior to the posterodorsal arm lobes. By Day 17, we could see distinct rudiments (developing juvenile bodies) on the larvae of Strongylocentrotus droebachiensis. We measured the anterior to posterior diameter of those rudiments as an indication of progress toward metamorphic competence. Rudiment size in the light and dark treatments was compared with a nested ANOVA (light as the main effect with beaker nested in light and larvae nested in both light and beaker). Rudiments did not appear on larvae of the other 2 species over the duration of the experiment.

Because we were interested in larval morphology and the potential effects of light on overall larval shape, we analyzed the remaining data with multivariate methods (PRIMER software) rather than comparing individual larval dimensions. We used a nested analysis of similarity (ANOSIM) to compare the shape of lar-

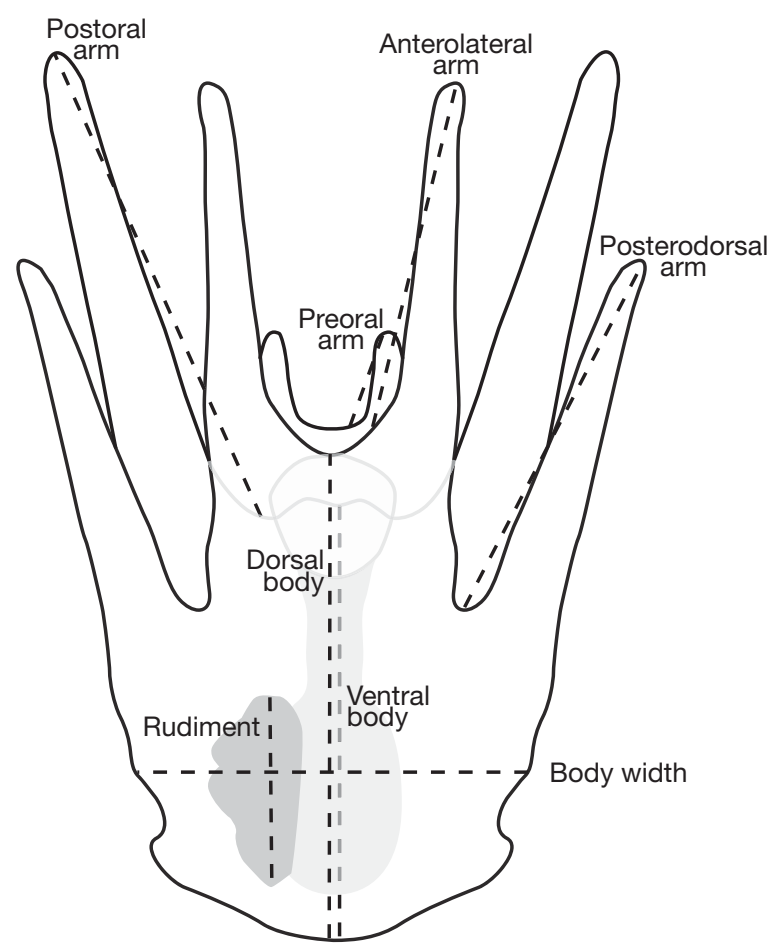

Fig. 2. Dorsal view of an echinopluteus larva showing dimensions measured to document larval morphology in the growth experiment. Dorsal body length was measured from the posterior tip of the larva to the cleft between the anterolateral arms. Ventral body length was from the posterior tip to the transverse band between the postoral arms 
vae in the dark and light treatments and to test for variability among beakers within each treatment. We ran the ANOSIM only for data collected on the last day of each experiment, assuming any differences in larval morphology would be most pronounced on that day. Prior to analysis, the data were 4 th root transformed to balance the contribution of the various larval dimensions to the ordination; Euclidean distance was the distance metric. Where we found significance, we used similarity percentages (SIMPER) analysis to see which larval dimensions contributed most to treatment differences.

To visualize changes in larval shape over the full period of the experiment, we also created multidimensional scaling (MDS) plots. To simplify presentation, we averaged the larvae within individual beakers on a given day to create one value per beaker. This allowed us to visually illustrate beaker-to-beaker variability within the treatments. We then averaged all beakers within a treatment, reducing the data to a single set of larval measurements for each treatment on each day, and connected sequential samples on the MDS. Changes in position of sequential points indicate

Table 1. Dendraster excentricus, Strongylocentrotus droebachiensis and $S$. franciscanus. Nested ANOVA results for the effects of light treatment, time-of-day and vial (nested in light and time) on ingestion rates of pluteus larvae. Significant effects $(\alpha=0.05)$ are shown in bold. Partial eta squared $\left(\eta^{2}\right)$ values are the proportion of the total variation explained by each factor (calculated as though that factor and its error were the only factors in the model)

\begin{tabular}{|c|c|c|c|c|c|}
\hline Source & SS & df & F & $\mathrm{p}$ & Partial $\eta^{2}$ \\
\hline \multicolumn{6}{|c|}{ Dendraster excentricus } \\
\hline Light & 1649.6 & 1 & 2.55 & 0.12 & 0.07 \\
\hline Time & 25772.3 & 3 & 13.29 & $<0.001$ & 0.55 \\
\hline $\mathrm{L} \times \mathrm{T}$ & 5216.5 & 3 & 2.69 & 0.06 & 0.20 \\
\hline Vial & 20682.3 & 32 & 1.06 & 0.37 & 0.07 \\
\hline Larvae & 262490.2 & 432 & & & \\
\hline Total & 315810.9 & 471 & & & \\
\hline \multicolumn{6}{|c|}{ Strongylocentrotus droebachiensis } \\
\hline Light & 1566.6 & 1 & 0.71 & 0.41 & 0.02 \\
\hline Time & 34965.5 & 3 & 5.31 & 0.006 & 0.39 \\
\hline $\mathrm{L} \times \mathrm{T}$ & 7331.4 & 3 & 1.11 & 0.36 & 0.12 \\
\hline Vial & 52720.2 & 24 & 1.82 & 0.01 & 0.12 \\
\hline Larvae & 383593.8 & 318 & & & \\
\hline Total & 480177.5 & 349 & & & \\
\hline \multicolumn{6}{|c|}{ Strongylocentrotus franciscanus } \\
\hline Light & 216.4 & 1 & 0.39 & 0.53 & 0.01 \\
\hline Time & 2290.8 & 3 & 1.38 & 0.26 & 0.11 \\
\hline $\mathrm{L} \times \mathrm{T}$ & 577.8 & 3 & 0.34 & 0.79 & 0.03 \\
\hline Vial & 17698.1 & 32 & 2.21 & $<0.001$ & 0.13 \\
\hline Larvae & 109569.1 & 439 & & & \\
\hline Total & 130352.2 & 478 & & & \\
\hline
\end{tabular}

changes in larval morphology (e.g. growth in arms, appearance of new arms, changes in body length and/or width). Larger distances indicate greater change. By plotting both light and dark treatments on the same MDS, we are able to visually compare morphology of larvae in the 2 treatments on each day. If light affected larval morphology, we expected the treatment lines to diverge over time. While these latter MDS plots do not show larva-to-larva or beaker-to-beaker variability, they do illustrate the global change in larval shape over time. The important beaker-to-beaker (within treatment) variability was retained in the ANOSIM and SIMPER analyses.

\section{RESULTS}

\section{Diel patterns in larval ingestion rates}

Short-term (15 min) exposures to light or dark did not significantly change ingestion rates in Dendraster excentricus, Strongylocentrotus droebachiensis or $S$. franciscanus plutei (Table 1). Though sample sizes were relatively low, Fig. 3 verifies that effects, if any, were small. The separation of the treatment means exceeded $10 \%$ in only 3 instances and there was no consistent direction to the pattern (e.g. ingestion was not consistently higher in the light than it was in the dark).

Larvae of Dendraster excentricus and Strongylocentrotus droebachiensis showed temporal patterns in ingestion rates while $S$. franciscanus larvae did not (Table 1, Fig. 3). Tukey's tests showed that D. excentricus larvae ingested significantly more beads in the midday (13:00 h) sample than at any other time. The larvae of $S$. droebachiensis fed most in the early morning (07:00 h) sample and least in the 19:00 h sample.

There was significant vial-to-vial variability in the data from Strongylocentrotus droebachiensis and $S$. franciscanus (Table 1). Despite the statistical significance (due to the large degrees of freedom in the denominators of the tests), the effect sizes were relatively small. Partial eta-squared values ranged from 0.13 to 0.16 , indicating that viability among vials accounted for only 13 to $16 \%$ of the overall (effect + error) variance.

\section{Light manipulation and larval feeding}

Though we saw no significant temporal pattern of feeding in our initial experiment with 8 d old Strongylocentrotus franciscanus larvae, our subsequent test with 22 d old larvae did reveal a time-of-day effect (Table 2). The pattern was similar to what we saw with Dendraster excentricus; ingestion rates were highest in the 13:00 h sample (Fig. 4). Three days of darkness did 


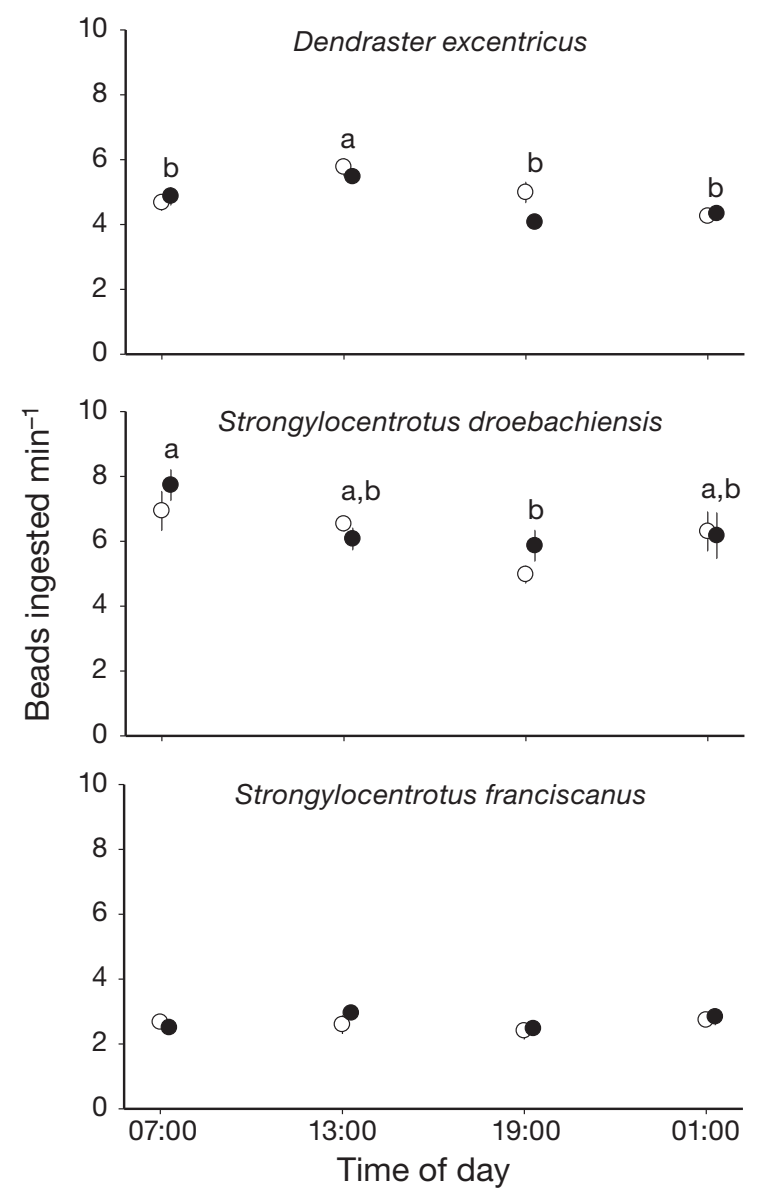

Fig. 3. Dendraster excentricus, Strongylocentrotus droebachiensis and $S$. franciscanus. Number of beads ingested by 6 to $8 \mathrm{~d}$ old pluteus larvae in light $(\mathrm{O})$ and dark $(0)$ treatments (means $\pm \mathrm{SE}$ ). All ingestion occurred during a single $15 \mathrm{~min}$ feeding trial. Prior to the experiment, all larvae were held on a 12:12 $\mathrm{h}$ light:dark cycle with lights turning on at 06:00 $\mathrm{h}$ and off at 18:00 h. Letters next to symbols show the result of Tukey's pairwise comparisons of the time points. Values with the same letter were statistically indistinguishable $(\alpha=0.05)$

not change feeding patterns in S. franciscanus. Larvae maintained the same feeding rhythm as those kept in their normal 12:12 $\mathrm{h}$ light:dark cycle. The absence of a significant light or light $\times$ time effect indicates that an internal feeding rhythm persists even when larvae experience several days of complete darkness.

The experimental tank was designed to produce distinct light differences between treatments while giving all larvae access to the same algal food. Light measurements showed clear differences in light intensity in light and dark beakers; light intensity in light and dark treatments was $59.7 \pm 9.6$ and $3.4 \pm 0.6 \mu$ mol photons $\mathrm{m}^{-2} \mathrm{~s}^{-1}$ (means $\pm \mathrm{SD}$ ), respectively.

Measurements of exchange rates between beakers and the experimental tank showed that the concentration of Rhodomonas sp. reached equilibrium within
Table 2. Strongylocentrotus franciscanus. Nested ANOVA results for the effects of light treatment, time-of-day and vial (nested in light and time) on ingestion rates of $22 \mathrm{~d}$ old larvae acclimated to complete darkness or a 12:12 h light:dark cycle for $3 \mathrm{~d}$ prior to the feeding trials. Significant effects $(\alpha=0.05)$ are shown in bold

\begin{tabular}{|lrrrll|}
\hline Source & \multicolumn{1}{c}{ SS } & df & \multicolumn{1}{c|}{$F$} & p & Partial $\eta^{2}$ \\
\hline Light & 369.8 & 1 & 0.27 & 0.60 & 0.02 \\
Time & 18710.7 & 1 & 14.12 & $\mathbf{0 . 0 0 3}$ & $\mathbf{0 . 5 6}$ \\
L $\times$ T & 130.4 & 1 & 0.09 & 0.75 & 0.01 \\
Vial & 14566.6 & 11 & 2.93 & $\mathbf{0 . 0 0 1}$ & $\mathbf{0 . 1 6}$ \\
Larvae & 74345.1 & 165 & & & \\
Total & 100122.6 & 179 & & & \\
\hline
\end{tabular}

3 min. Hence, larvae should not have been able to deplete algae in a beaker faster than it could be replaced by the mixing process. After $24 \mathrm{~h}$ of mixing, we could detect no significant difference in the chl a fluorescence values for the light and dark treatment beakers $(F=0.19, \mathrm{p}=0.66)$.

\section{Larval growth and morphology}

Larvae sampled during the long-term growth experiment consistently had algae in their guts, suggesting that differential food availability in light and dark beakers did not produce treatment differences. Light did not significantly affect morphology of Strongylocentrotus droebachiensis or $S$. franciscanus larvae. There was considerable beaker-to-beaker variability in larval features (Fig. 5) and ANOSIM indicated that, on the final day of sampling, variability was significant for all 3 species (Dendraster excentricus Global $\mathrm{R}=$ 0.27, $\mathrm{p}=0.001 ;$ S. droebachiensis Global $\mathrm{R}=0.24, \mathrm{p}=$ 0.01 ; . franciscanus Global $\mathrm{R}=0.31, \mathrm{p}=0.01$ ). However, we found no light effects for $S$. droebachiensis (Global R $=0.04, \mathrm{p}=0.12$ ) or $S$. franciscanus (Global $\mathrm{R}=0.01, \mathrm{p}=0.40$ ). MDS plots for both sea urchin species showed distinct changes in larval morphology

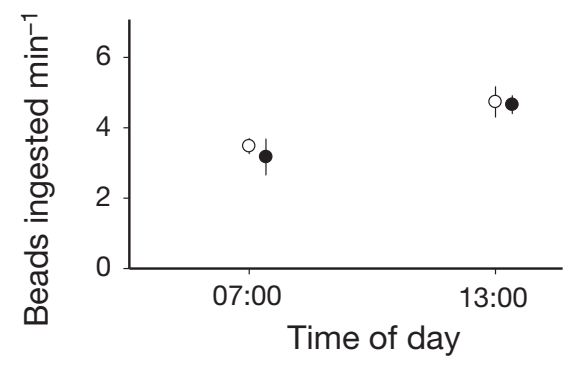

Fig. 4. Strongylocentrotus franciscanus. Number of beads ingested by $22 \mathrm{~d}$ old larvae in light $(\mathrm{O})$ and dark (O) treatments after a $3 \mathrm{~d}$ acclimation to the treatment (light was a 12:12 h light:dark cycle; dark was complete darkness). Experiments ran for $15 \mathrm{~min}$. Means $\pm \mathrm{SE}$ 


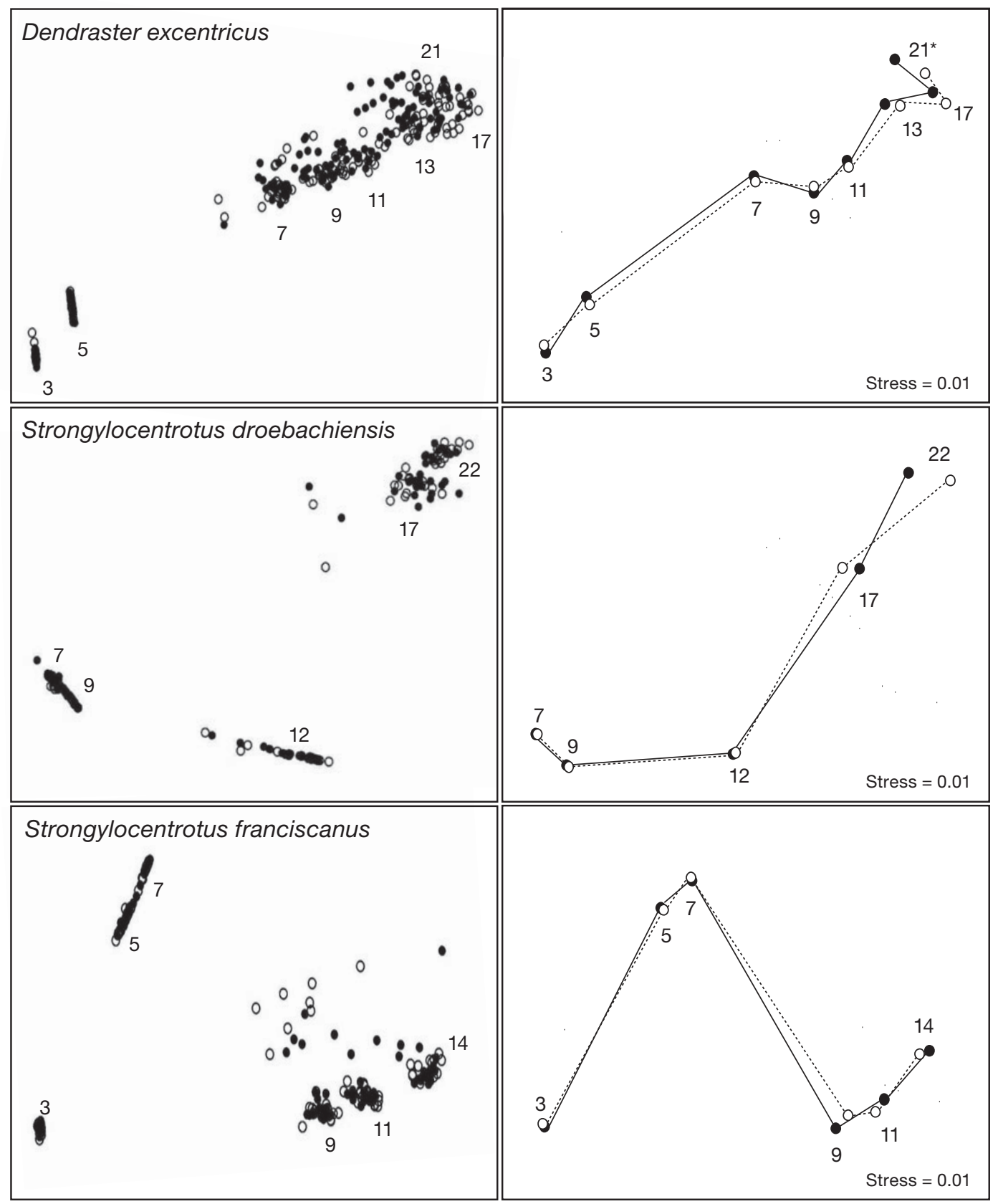

Fig. 5. Dendraster excentricus, Strongylocentrotus droebachiensis and S. franciscanus. Multidimensional scaling (MDS) ordination for morphology of larvae exposed to light (o) or dark (•) treatments. Left-hand panels: averaged shape of 5 to 8 larvae sampled from each of 20 beakers per treatment per day (shape based on measurements of 7 larval dimensions). Numbers: age of larvae in days since fertilization. ANOSIM comparisons of treatments were made on the final day of measurements in each of these panels. Right-hand panels: Average dimensions of all larvae within all 20 beakers of each treatment were averaged to produce the MDS figures. Lines were added to emphasize change over time in each species. Change in position of the points over time indicates changes in shape and size of the larvae (larger distances indicate greater changes). The low stress values $(<0.05)$ indicate an excellent fit of the 2-dimensional ordination plot to the multivariate data set

over time, but the light and dark treatments tracked one another closely (Fig. 5).

In contrast to the larvae of the sea urchin species, plutei of the sand dollar Dendraster excentricus did show a morphological response to light (Fig. 5). For the first $11 \mathrm{~d}$ of the experiment, larval morphology was similar in the light and dark treatments. However, after that date, the larvae began to diverge in form, and ANOSIM showed significant treatment differences on the final day of sampling (Global $\mathrm{R}=0.32, \mathrm{p}=0.001$ ). 
SIMPER analysis indicated that the treatment difference was due almost entirely to differences in arm lengths: preoral arm length $(35.4 \%$ contribution to the treatment difference), postoral arm length (21.2\% contribution), posterodorsal arm length (19.4\% contribution), anterolateral arm length (17.9\% contribution). These arms were, on average, 19 to $27 \%$ shorter in larvae held in continuous darkness (Fig. 6). Dorsal length, ventral length, and body width together accounted for barely $6 \%$ of the difference between treatments.

Though the morphology of Strongylocentrotus droebachiensis larvae was not affected by the light treatments, juveniles of this species may carry over effects of larval light exposure. The juvenile rudiments of $S$. droebachiensis held in the dark were $196.3 \pm 10.2 \mu \mathrm{m}$ while those of larvae in the 12:12 h light:dark cycle were only $170.0 \pm 10.0 \mu \mathrm{m}$ in diameter (means $\pm \mathrm{SD}$ ). This $15 \%$ difference in diameter was statistically significant $(F=5.83$, $\mathrm{p}=0.02)$ despite significant $(F=7.19, \mathrm{p}<0.01)$ beaker-tobeaker variability within the light treatments.

\section{DISCUSSION}

Contrary to our expectations, manipulating light exposure had no measurable effect on feeding rates of larvae of Strongylocentrotus droebachiensis, S. franciscanus, or Dendraster excentricus. Altering the light regime of the larvae, even for several days, did not produce the change in ingestion rate that might be expected if these larvae normally benefit from some kind of light-enhanced digestion.

The absence of a response in our experiment indicates that larval feeding behavior does not immedi-

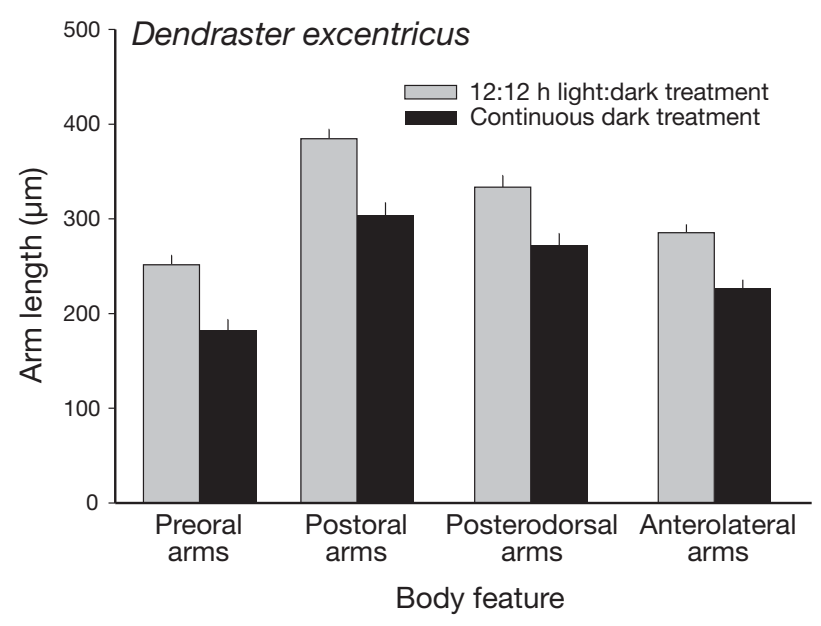

Fig. 6. Dendraster excentricus. Length of larval arms (means $+\mathrm{SE}$ ) in light- and dark-treated larvae. Plotted dimensions are those shown by similarity percentage (SIMPER) analysis to be most important in distinguishing larvae from the 2 treatments ately change when light levels increase or decrease (at least at the intensities we used). The densities of particles we used were near those known to produce maximum clearance rates in larval echinoids (Strathmann 1971), and the clearance rates we obtained for Dendraster excentricus and Strongylocentrotus droebachiensis ( 0.5 to $2.0 \mu \mathrm{lmin}^{-1}$ ) are near the maximum clearance rates obtained by Hart \& Strathmann (1994) for larval $D$. excentricus of approximately the same age. Therefore, larvae of those species were apparently feeding near their maximum capacity in both light treatments. Some factor unassociated with the light treatment may have been responsible for the much lower overall clearance rates of $S$. franciscanus larvae.

It is possible that the concentrations of beads and Rhodomonas used in our experiment were high enough to saturate ingestion by larvae in all treatments. If the larval guts were consistently full, there would be little room to detect light-induced differences. In each of our species, however, we saw at least 2 -fold differences in numbers of ingested beads among larvae within the treatments, indicating that the larvae were not all simply saturated in their feeding capabilities.

A second possibility is that our experimental light levels were too low to produce any feeding response. Strom (2001) demonstrated increased feeding by ciliates exposed to $100 \mu \mathrm{mol}$ photons $\mathrm{m}^{-2} \mathrm{~s}^{-1}$. The light level in our laboratory treatment was only $50 \mu \mathrm{mol}$ photons $\mathrm{m}^{-2} \mathrm{~s}^{-1}$. If higher illuminations are necessary to trigger increased feeding, we missed the effect due to low light intensities.

Finally, if feeding rate is controlled by physiology rather than behavior, as suggested for protozoans (Strom 2002), our experiments may have simply been too brief to enhance digestive throughput sufficiently to increase ingestion. The increased feeding described by Strom (2001) occurred within a 45 min test period and was likely linked to the physiology of digestion (i.e. photooxidation increased digestion rates, decreasing vacuole passage time and allowing for increased ingestion). Had we run our experiment longer, breakdown of the Rhodomonas cells ingested with the beads may have triggered increased feeding. As performed, our experiment was a test of the direct effect of light on feeding behavior. Measuring indirect effects of light on ingestion rate via a light-induced digestive boost may require longer observation of individual larvae under carefully controlled conditions of light and food.

While we could find no light-controlled feeding trigger, we did find evidence that light exerts some longerterm control on feeding. Our 3 test species showed significant temporal variability in feeding. In 2 species, the temporal feeding patterns were evident in the initial 15 min ingestion experiment. In both cases, the peak feeding occurred during daylight hours. The third species, Strongylocentrotus franciscanus, did not 
show any statistically significant pattern in the initial trial. However, when experiments were performed with slightly older larvae, we found the same pattern of high daytime feeding. Since light was the only factor that consistently varied in our cultures, we believe that it was the cause of the temporal feeding patterns we saw. Our experiments did not indicate why these patterns exist, but the fact that they persisted in S. franciscanus larvae even after $3 \mathrm{~d}$ of continuous darkness suggests they are real.

Diel feeding patterns have been demonstrated for a variety of zooplanktonic invertebrates. Usually, however, the feeding cycle is linked to vertical migration; the phytoplankton grazers move to surface waters to feed at night when they are less obvious to visual predators (e.g. Durbin et al. 1990, Leising et al. 2005). Pennington \& Emlet (1986) studied the vertical distribution of Dendraster excentricus larvae in outdoor 25001 floating enclosures. The larvae showed the migratory pattern typical of many other zooplankton. They moved deeper during the day (to the maximum enclosure depth of $3.2 \mathrm{~m}$ ) and returned toward the surface in the evening. Under these conditions, the larvae might be expected to feed most when they are near the surface (during nighttime). This is opposite the pattern we saw with all 3 species; feeding was consistently highest during daylight hours. Again, experiments with more realistic light levels would help validate these laboratory results.

While the effects of light on larval feeding behavior were subtle, effects on larval morphology were clearer. Morphological plasticity in echinoid larvae is well documented. Food-limited plutei may shift resources into larval arms and ciliated feeding bands (i.e. feeding features) at the expense of juvenile structures (Boidron-Metairon 1988, Strathmann et al. 1992, Fenaux et al. 1994). The larval arms bear up to $74 \%$ of the ciliated band used in feeding, and Strathmann (1971) found a linear relationship between length of the ciliated band and the maximum rate at which larvae clear food from the surrounding water. The formation of new arms and/or the elongation of existing arms, therefore, increases feeding capacity (McEdward 1984, Fenaux et al. 1985, Hart \& Strathmann 1994).

Divergence in body forms of Dendraster excentricus larvae held in light and dark conditions became apparent 17 to $21 \mathrm{~d}$ after initiation of the experiment. We do not know whether changes in Strongylocentrotus franciscanus or S. droebachiensis larval morphology would appear later in development. It is also possible that running the experiments with lower food concentrations would magnify light effects, producing more treatment differences.

The changes we saw in Dendraster excentricus larval morphology were opposite to our predictions. Larvae held in a 12:12 h light:dark cycle (hypothesized to receive a light-induced digestive boost) actually developed the longer arms generally associated with low nutrition. A possible explanation for this result is that larvae in the dark fed more successfully because prey in that treatment were easier to catch. However, none of the phytoflagellates used as prey show obvious phototactic or photokinetic behavior in the laboratory (S. Strom pers. com.). Furthermore, mixing in the tank should have overwhelmed any differences in prey swimming. Eliminating this possibility, however, will require study of individual prey species' behavior under variable light conditions.

While our study focused on the potential effects of light on larval shape, it is possible that, rather than affecting morphology, light simply affected rates of development. The difference in morphology of Dendraster excentricus larvae on Day 21 was attributed to differences in all 4 pairs of larval arms. Interestingly, the difference in the relative lengths of all arm pairs in light and dark treatments was nearly equal (60 to $80 \mu \mathrm{m})$ despite much larger differences in the absolute arm length, indicating that arms may simply be growing more slowly. This possibility is contradicted, however, by the Stronglylocentrotus droebachiensis data. After $18 \mathrm{~d}$ of treatment, larvae in light and dark treatments were statistically indistinguishable, except for the rudiment. Larvae held in complete darkness had produced significantly larger rudiments, suggesting that those larvae had greater energy to allocate to development of juvenile structures and were moving more quickly toward metamorphosis.

The smaller rudiments we saw in light-treated Strongylocentrotus droebachiensis suggest that light may retard development, possibly by changing ingestion or assimilation. Lesser \& Barry (2003) reported that even short exposures to UV light have strong negative effects on the larvae of $S$. droebachiensis. Pennington \& Emlet (1986) similarly found that UV can affect swimming behavior, development and survival of Dendraster excentricus larvae. Larvae exposed to sunlight moved deeper in the water column, presumably to avoid damaging light levels. To our knowledge, no one has specifically tested for chronic effects of photosynthetically active radiation (PAR) on echinoid larvae, but Bingham \& Reitzel (2000) demonstrated that visible light alone can damage invertebrate larvae.

The light levels in our experiments ranged between 50 and $60 \mu \mathrm{mol}$ photons $\mathrm{m}^{-2} \mathrm{~s}^{-1}$. In the field, we have measured similar light intensities at depths of 5 to $10 \mathrm{~m}$ (depending on water turbidity) on cloudless summer days. Echinoid larvae in Puget Sound appear to dwell largely in surface waters, usually $<6 \mathrm{~m}$ deep (Emlet 1986, Pennington \& Emlet 1986). During the springtime and early summer when larvae are present, they 
could easily experience light intensities many times higher than those we used (intensities at the surface commonly reach $1500 \mu \mathrm{mol}$ photons $\mathrm{m}^{-2} \mathrm{~s}^{-1}$, unpubl. data). Given that we detected light effects under relatively low-light conditions, there is clear potential for much stronger effects on behavior, morphology and development of larvae under more realistic light conditions. A better understanding of those effects and whether they occur under field conditions could provide important insight into larval behavior and the consequences of that behavior on fundamental ecological processes such as dispersal or recruitment.

Acknowledgements. We thank S. Strom, S. Menden-Deuer, B. Miner, G. McKeen and N. Schwarck for helpful discussion. G. Landis constructed our experimental tank. S. Sulkin made laboratory space available at the Shannon Point Marine Center.

\section{LITERATURE CITED}

Bingham BL, Reitzel AM (2000) Solar damage to the solitary ascidian, Corella inflata. J Mar Biol Assoc UK 80:515-521

Boidron-Metairon IF (1988) Morphological plasticity in laboratory-reared echinoplutei of Dendraster excentricus (Eschscholtz) and Lytechinus variegatus (Lamark) in response to food conditions. J Exp Mar Biol Ecol 119:31-41

Durbin AG, Durbin EG, Wlodarczyk E (1990) Diel feeding behaviour in the marine copepod Acartia tonsa in relation to food availability. Mar Ecol Prog Ser 68:23-45

Emlet RB (1986) Larval production, dispersal, and growth in a fjord: a case study on larvae of the sand dollar Dendraster excentricus. Mar Ecol Prog Ser 31:245-254

Fenaux L, Cellario C, Etienne M (1985) Variation in the ingestion rate of algal cells with morphological development of larvae of Paracentrotus lividus (Echinodermata: Echinoidea). Mar Ecol Prog Ser 24:161-165

Fenaux L, Strathmann MF, Strathmann RR (1994) Five tests of food-limited growth of larvae in coastal waters by comparisons of rates of development and form of echinoplutei. Limnol Oceanogr 39:84-98

Fotel FL, Jensen NJ, Wittrup L, Hansen BW (1999) In situ and laboratory growth by a population of blue mussel larvae (Mytilus edulis L) from a Danish embayment, Knebel Vig. J Exp Mar Biol Ecol 233:213-230

Hansen BW (1999) Cohort growth of planktotrophic polychaete larvae - are they food limited? Mar Ecol Prog Ser 178:109-119

Hart MW, Strathmann RR (1994) Functional consequences of phenotypic plasticity in echinoid larvae. Biol Bull 186: 291-299

Editorial responsibility: Pei-Yuan Qian, Kowloon, Hong Kong SAR
Leising AW, Pierson JJ, Cary S, Frost BW (2005) Copepod foraging and predation risk within the surface layer during night-time feeding forays. J Plankton Res 27:987-1001

> Lesser MP, Barry TM (2003) Survivorship, development, and DNA damage in echinoderm embryos and larvae exposed to ultraviolet radiation (290 - $400 \mathrm{~nm})$. J Exp Mar Biol Ecol 292:75-91

McEdward LR (1984) Morphometric and metabolic analysis of growth and form of an echinopluteus. J Exp Mar Biol Ecol 82:259-287

Morgan SG (1995) Life and death in the plankton: larval mortality and adaptation. In: McEdward L (ed) Ecology of marine invertebrate larvae. CRC press, Boca Raton, FL, p 279-322

Olson RR, Olson MH (1989) Food limitation of planktotrophic marine invertebrate larvae: Does it control recruitment success? Annu Rev Ecol Syst 20:225-247

> Paulay G, Boring L, Strathmann RR (1985) Food limited growth and development of larvae: experiments with natural sea water. J Exp Mar Biol Ecol 93:1-10

> Pennington JT, Emlet RB (1986) Ontogenetic and diel vertical migration of a planktonic echinoid larva, Dendraster excentricus (Eschscholtz): occurrence, causes, and probable consequences. J Exp Mar Biol Ecol 104:69-95

Rumrill SS (1990) Natural mortality of marine invertebrate larvae. Ophelia 32:163-198

> Strathmann RR (1971) The feeding behavior of planktotrophic echinoderm larvae: mechanisms, regulation, and rates of suspension feeding. J Exp Mar Biol Ecol 6:109-160

> Strathmann RR, Fenaux L, Sewell AT, Strathmann MF (1992) Heterochronic developmental plasticity in larval sea urchins and its implications for evolution of nonfeeding larvae. Evolution 46:972-986

Strom SL (2001) Light-aided digestion, grazing and growth in herbivorous protists. Aquat Microb Ecol 23:253-261

> Strom SL (2002) Novel interactions between phytoplankton and microzooplankton: their influence on the coupling between growth and grazing rates in the sea. Hydrobiologia 480:41-54

Sulkin S, Lehto J, Strom S, Hutchinson D (1998) Nutritive role of protists in the diet of the first stage larvae of the Dungeness crab Cancer magister. Mar Ecol Prog Ser 169: $237-242$

Thorson G (1950) Reproductive and larval ecology of marine bottom invertebrates. Biol Rev Camb Philos Soc 25:1-45

Verity PG (1991) Measurement and simulation of prey uptake by marine planktonic ciliates fed plastidic and aplastidic nanoplankton. Limnol Oceanogr 36:729-750

Young CM, Chia FS (1987) Abundance and distribution of pelagic larvae as influenced by predation, behavior, and hydrographic features. In: Giese AC, Pearse JS, Pearse VB (eds) Reproduction of marine invertebrates. IX. General aspects: seeking unity in diversity. Blackwell Scientific Publication, Palo Alto, CA, p 385-463

Submitted: July 29, 2009; Accepted: January 12, 2010

Proofs received from author(s): March 18, 2010 